\title{
A Game-Theoretic Model to Analyze Value Creation with Simultaneous Cooperation and Competition of Supply Chain Partners
}

\author{
F. Kafi and S. M. T. Fatemi Ghomi \\ Department of Industrial Engineering, Amirkabir University of Technology, Hafez Avenue No. 424, Tehran 15916-34311, Iran \\ Correspondence should be addressed to S. M. T. Fatemi Ghomi; fatemi@aut.ac.ir
}

Received 24 January 2014; Accepted 11 February 2014; Published 13 March 2014

Academic Editor: Matjaž Perc

Copyright (C) 2014 F. Kafi and S. M. T. Fatemi Ghomi. This is an open access article distributed under the Creative Commons Attribution License, which permits unrestricted use, distribution, and reproduction in any medium, provided the original work is properly cited.

\begin{abstract}
There is a rising trend in supplying chain management to employ simultaneous cooperation and competition (coopetition) among supply chain partners as an efficient strategy to create value. There exist, however, few models which analyze coopetitive situations mathematically. Cooperative game theory is the common tool in analyzing cooperative situations. However, the term "cooperative" in "cooperative game theory" is absolutely misleading since it ultimately leads to competition analysis and ignores the internal structure of the cooperation. Coopetition, however, results in structural transformations in players. Therefore, we require a mathematical modeling approach which takes into account the internal structural changes due to cooperation among competitors. In so doing, in this paper we propose, we assume that those parameters of each firm's profit function are subject to transformation by cooperation as a function of cooperation level so as to determine the right level of cooperation and production of firms while considering technical cooperation between them. Furthermore, we demonstrate the results of applying the idea to a supply chain situation where two similar suppliers participate. We conclude that under intuitive conditions coopetition strategy is superior to the pure competitive relationship between the suppliers in terms of profitability which validates the previous empirical results mathematically.
\end{abstract}

\section{Introduction}

Recent global economic recession seems to have led surviving supply chains to employ strategies and tools that enhance the creation of value at less cost than ever before among which the emerging role of collaboration in improving supply chain value creation system is highly intensified both by academia and practitioners. For instance, Walker [1] introduces "velocity, variability, vocalizes, visualize, and value" as five principles of supply chain networks. He highlights the emergence of collaboration in supply chain in "visualize" and "value" principles which critically questioning the local optimization within "the four walls of any single trading partner" and stressing collaboration in the chain so that trading partners can offer the maximum possible value to the market. Moreover, Wadhwa et al. [2] found that cooperation is a vital factor in improving supply chain performance. They also stress the role of information technology as a supporting enabler for firms involved in cooperation.

Traditionally, however, collaboration forms among partners with fully convergent goals so that cooperating competitors are unimaginable at the first thought. Cooperation among competitors or simply coopetition (Brandenburger and Nalebuff [3]) calls for sharing knowledge, joint technology development, market expansion through standard setting, and finally full business integration among partners with partial congruent goals (Dagnino and Padula [4]). Therefore, coopetition enhances the value creation system in a supply chain through sharing costs, risks, and resources.

Despite the significance of coopetition in reshaping the value net of a supply chain and its emerging practice in reallife cases, the amount of academic research in this arena is still quite limited (Dagnino and Rocco [5], Eikebrokk and Olsen [6]). The limitation even worsens as far as analytical 
models are concerned. There are few cases where the concept of coopetition is analytically studied to elaborate on its facets. Gurnani et al. [7], for example, study "the impact of pricing product pricing and timing of investment decisions on supply chain coopetition." One drawback of the study seems to be that they assume coopetition does not have any real impact on different aspect of each firm's structure including its production technology and cost structure. In other words, in their model coopetition is interpreted at an initial level of mere exchange of knowledge. In contrast, more profound levels of coopetition (i.e., joint technology development, market expansion) are solely studied empirically (Table 1) and an analytical model to validate findings seems to be missing.

Consequently, the main issue we address in this paper is proposing a modeling approach to examine deeper levels of coopetition mathematically. Cooperative game theory is the common tool to analyze cooperative settings (Nagarajan and Sošić [8]). One drawback with cooperative game theory is that it focuses on given payoff values for each possible coalition and ignores the internal structure of the cooperation. However, in coopetition we require to consider structural transformations of the partners in the model. In particular, the cost structure of firms evolves as firms expand their cooperation. Therefore, we need a mathematical modeling approach to consider the cooperation-based structural changes which in turn paves the way to a more real analysis of the relationship. In so doing, in this paper we propose, we assume that those parameters of each firm's profit function are subject to transformation by cooperation as a function of cooperation level. We then apply our idea to a situation where two similar suppliers cooperate to reduce production costs and compete in the market of their single product. Our mathematical analysis reveals that under intuitive conditions, the coopetition strategy is superior to the pure competitive relationship between suppliers in terms of profitability which validates the previous empirical results mathematically.

Therefore, our main contribution in this paper is a mathematical procedure to model coopetition which can pave the way for future research in the analysis of coopetitive situations. The remainder of this paper is as follows. In Section 2 we offer a brief review of the coopetition concept. In Section 3, the way coopetition modeled mathematically is fully explained. Section 4 discusses findings and results of the analysis. Finally, Section 5 presents the conclusion of the paper and some recommendations for future research.

\section{Coopetition: Literature Review}

"Coopetition" is a business strategy in which firms simultaneously cooperate and compete with each other, which are traditionally regarded as two opposite sides of the same coin. The term coopetition is originally attributed to Ray Noorda, the first CEO of Novell Software company who applied it in early 1990's to express his business philosophy of "partner with anybody and everybody that made sense" (Lipnack and Stamps [51]). Later, Brandenburger and Stuart [52] and Brandenburger and Nalebuff [3] made the term known to the business strategy research community. The

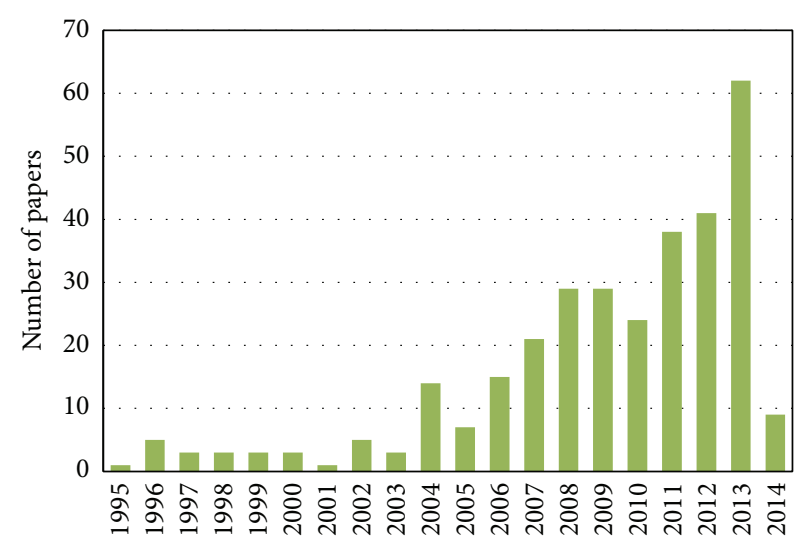

FIGURE 1: Coopetition research quantity during 1995-2014 in http://www.Sciencedirect.com/ as the one of January 2014.

main strength of the coopetition idea is not only playing the game of the business right but also playing the right game which is created by reshaping the value creation system of the firm through its cooperation with its customers, suppliers, complementors, and competitors (Brandenburger and Nalebuff [3]).

Browning et al. [53] employ the complexity theory to study the case of SEMATECH, a consortium of 14 US semiconductor manufacturers. They find SEMATECH as a successful symbol of cooperation in which "bloody enemies" cooperate, the secret of success lying on agreed upon boundaries of cooperation due to a shift in managers' mindset. Lado et al. [54] suggest the concept of "syncretic rent-seeking behavior" through which a greater long-run economic accomplishment is expected due to simultaneous competition and cooperation. "Rent seeking" is the pursuit of resources required by a firm to manage strategies that lead to enhancement of value and generate unexpected economic gains which realize via coopetition. Bengtsson and Kock [9] empirically examine two Swedish and one Finnish industries and find that there is a tendency among firms to cooperate in such areas as R\&D activities which are distant from customers and compete in activities such as differentiating a new product which are closer to customers. Gnyawali and Madhavan [55] analyze the influence of "network of cooperative linkages among competitors on their competitive behavior toward each other" using an embeddedness perspective. They find that competitors are subject to certain network constraints which do not allow them acting in a free competitive manner as if they were isolated islands. Through a conceptual model, they demonstrate the structural properties of firms and their network impact on network members' interaction.

The metamorphosis of coopetition literature from 1995 to 2014 is reviewed in Table 1. It shows the major journal articles published during this period in which coopetition is analyzed in various research areas. Figure 1 also shows a rising trend in the number of research works published with the main theme of coopetition in Sciencedirect.com as the one of January 2014 which seems still relatively limited and necessitates more research efforts, particularly in the area of analytical models. 
TABLE 1: The evolution of coopetition literature during 2000-2014.

\begin{tabular}{|c|c|c|c|}
\hline Authors & Year & Research Area & Methodology \\
\hline Bengtsson and Kock [9] & 2000 & Business networks & Empirical \\
\hline Carayannis and Alexander [10] & 2001 & Satellite industry & Empirical \\
\hline De Vlaam and De Jong [11] & 2002 & Infrastructure sector & Empirical \\
\hline Levy et al. [12] & 2003 & Knowledge sharing management & Empirical \\
\hline Soekijad and Andriessen [13] & 2003 & Knowledge sharing management & Empirical \\
\hline Song $[14]$ & 2003 & Port management & Empirical \\
\hline Luo [15] & 2004 & Multinational corporations & Conceptual \\
\hline Cheng [16] & 2005 & ICT industry & Empirical \\
\hline Luo [17] & 2005 & Multinational corporations & Conceptual \\
\hline Gnyawali et al. [18] & 2006 & Competitive behavior & Empirical \\
\hline Luo et al. [19] & 2006 & Cross-functional relationships & Empirical \\
\hline Reaidy et al. [20] & 2006 & Manufacturing control systems & Analytical \\
\hline Luo [21] & 2007 & Global competition & Conceptual \\
\hline Brandes et al. [22] & 2007 & Automotive industry & Conceptual \\
\hline Gurnani et al. [7] & 2007 & Supply chain management & Analytical \\
\hline López-Gómez and Molina-Meyer [23] & 2007 & Dynamical systems & Analytical \\
\hline Barretta [24] & 2008 & Health-care sector management & Empirical \\
\hline Bojar and Drelichowski [25] & 2008 & Agriculture sector management & Empirical \\
\hline Chin et al. [26] & 2008 & Manufacturing strategy management & Empirical \\
\hline Eriksson [27] & 2008 & Buyer-supplier relationships & Empirical \\
\hline Min et al. [28] & 2008 & Cluster supply chains & Analytical \\
\hline Wang and Krakover [29] & 2008 & Tourism industry & Empirical \\
\hline Bakshi and Kleindorfer [30] & 2009 & Supply chain management & Analytical \\
\hline Baumard [31] & 2009 & SME innovation strategies & Conceptual \\
\hline Brolø [32] & 2009 & Financial sector & Empirical \\
\hline Cassiman et al. [33] & 2009 & Research and development & Empirical \\
\hline Czakon [34] & 2009 & SME relationships & Empirical \\
\hline Gnyawali and Park [35] & 2009 & SME technological innovations & Conceptual \\
\hline Gueguen [36] & 2009 & Information technology sector & Empirical \\
\hline Mione [37] & 2009 & Institutional standards development & Empirical \\
\hline Nadin [38] & 2009 & Automotive industry & Empirical \\
\hline Ritala and Hurmelinna-aukkanen [39] & 2009 & Research and development & Conceptual \\
\hline Robert et al. [40] & 2009 & SME relationships & Empirical \\
\hline Tidström [41] & 2009 & Business networks & Empirical \\
\hline Watanabe et al. [42] & 2009 & Research and development & Empirical \\
\hline Wu et al. [43] & 2009 & Supply chain management & Empirical \\
\hline Kovács and Spens [44] & 2010 & Relief supply chain management & Conceptual \\
\hline Wilhelm [45] & 2011 & Supply chain relations & Empirical \\
\hline Akdoğan and Cingšz [46] & 2012 & Small and medium sized businesses & Empirical \\
\hline Dahl [47] & 2013 & Industrial marketing & Empirical \\
\hline Tidström [48] & 2013 & Industrial marketing & Empirical \\
\hline Achcaoucaou et al. [49] & 2014 & Knowledge sharing & Empirical \\
\hline Karhu et al. [50] & 2014 & Mobile ecosystems & Empirical \\
\hline
\end{tabular}

\section{The Main Idea: Coopetitively Influenced Parameters as Functions}

In coopetition, competitors cooperate with each other, the success of which depends on many factors. For example, Wang et al. [56] find that an optimal resolution of social dilemmas is warranted by an intermediate density of sufficiently strong interactions between network partners. Wang et al. [57] also analyze the impact of population density on the evolution cooperation in structured populations. The robustness of cooperation is also enhanced by social punishment [58] and heterogeneity in aspirations is found to be an important factor for the sustainability of cooperation in structured populations [59]. Furthermore, 
cooperation is promoted best by an intermediate aspiration level [60]. Therefore, in order to form a successful cooperative relationship, the relationship must be managed systematically so as to provide necessary success conditions. Hence, the important and interesting question is how to model a cooperative relationship mathematically. Cooperative game theory is the common tool in analyzing cooperative situations. However, as Shoham and Leyton-Brown [61] indicate that the term "cooperative" in "cooperative game theory" "can be misleading" since it does not convey the hidden competitive nature of the theory precisely, in cooperative game theory, "cooperative" is indicative of the idea that the basic unit of modeling is a group of actors contrasting noncooperative game theory where the basic unit of modeling is an individual actor. Therefore, in cooperative game theory, players are groups of actors whose group-based capabilities are analyzed to determine coalition patterns and payoff allocation schemes leading once again to competition analysis similar to noncooperative game theory via focusing on given payoff values for each possible coalition and ignoring the internal structure of the cooperation [61].

Coopetition, however, leads to structural transformations in players (see e.g., $[3,4]$ ). Therefore, we require a mathematical modeling approach which takes into account the internal structural changes due to cooperation among competitors. As a result, in this paper we propose a general mathematical coopetition modeling approach. We need the following definitions.

Consider the function $f: \mathbb{R}^{n} \rightarrow \mathbb{R}$. We define the set $V_{f}$ as the set of input variables of function $f$. Note that $\left|V_{f}\right|=n$. The set of all the real valued functions on the domain $\mathbb{R}^{n}$ is denoted by $F(n)$. The set $E_{y}^{f} \subset F(n+m)$ is called the set of extended functions of function $f$ with respect to the vector of variables $y$ if for all $e \in E_{y}^{f}$ the relation $V_{e} \supset V_{f}$ holds, where $m \geq 1$.

The set of all noncooperative games is denoted by $G$. Consider the game $g \in G$ and let $N_{g}$ denote the set of game $g$ players. The set $F_{g}$ shows the set of profit functions of players of game $g$. For each function $f_{i} \in F_{g}$, the set $V_{f_{i}}^{+}$is the set of decision variables controlled by player $i$ and the set $V_{f_{i}}^{-}$is the set of decision variables controlled by all players except player $i$. Note that $V_{f_{i}}=V_{f_{i}}^{+} \cup V_{f_{i}}^{-}$and $V_{f_{i}}^{+} \cap V_{f_{i}}^{-}=\emptyset$. The set $H_{w}^{g} \subset G$ is called the set of extended games of game $g$ with respect to the vector of variables $W$ if for all $h \in H_{w}^{g}$ there exists a set $T \in F_{h}$ with $|T| \geq 2$ such that the following conditions hold:

(i) $\left(\forall f_{2} \in T \exists f_{1} \in F_{g} \exists y \subset W \exists e \in E_{y}^{f_{1}}\right)\left(f_{2}=e\right)$,

(ii) $\left(\forall w \in W \exists ! i \in N_{g} \exists ! j \neq i \in N_{g}\right)\left(w \in V_{f_{i}}^{+} \Rightarrow w \in V_{f_{j}}^{-}\right)$, where $\exists$ ! denotes unique existence quantifier.

The game $g$ is called cooperable with respect to the vector of variables $W$ if there exists a function $\phi$ such that $\phi(g, W) \in$ $H_{W}^{g}$ and

$$
\begin{array}{r}
\left(\forall w \in W \forall i \in N_{g} \forall f_{2}^{i} \in F_{\phi(g, W)} \exists ! f_{1}^{i} \in F_{g}\right) \\
\left(w \in V_{f_{2}^{i}} \Longrightarrow f_{2}^{i}\left(x_{2}^{*}\right) \geq f_{1}^{i}\left(x_{1}^{*}\right)\right),
\end{array}
$$

where $x_{1}^{*} \in \mathbb{R}^{n}$ and $x_{2}^{*} \in \mathbb{R}^{n+m}$ are Nash equilibria of game $g$ and game $\phi(g, W)$, respectively.

The main idea behind the above modeling approach is to reflect the impact of cooperation on cooperating competing firms in mathematical models by assuming that the main parameters are themselves a function of the level of effort contributed by each player to the cooperation. For example, if the purpose of firms is to cooperate so as to reduce unit production cost $c$, the unit production cost $c$ of the product would not be an exogenous parameter of the model. It would, however, be a function of the total cooperative effort of each firm. More formally, let $w_{i}$ denote the cooperative effort level of firm $i$. The unit production cost in the previous example is then $C\left(w_{1}, w_{2}\right)$.

In order to show the applicability of the idea, we apply it in a classic Cournot duopoly game [62]. Cournot games are extensively applied to analyze firms' competition on their production levels. In such games, the inverse demand function is linear in total production of firms, whose associated individual production level is shown by $q_{i}$ and the unit production cost $c$ is assumed to be fixed. Therefore, the mathematical model of firm $i$ 's profit function $p_{i}$ is

$$
\begin{array}{r}
p_{i}\left(q_{1}, q_{2}\right)=\left(a-b\left(q_{1}+q_{2}\right)\right) q_{i}-c q_{i}, \quad a>0, \quad b>0, \\
i=1,2,
\end{array}
$$

where $a$ and $b$ are fixed exogenous parameters.

Although Cournot games are explored well both theoretically and computationally (see e.g., Han and Liu [63]), Cournot games with simultaneous cooperation and competition are not studied because the main nature of research in coopetition has been empirical or conceptual since the introduction of the concept in 1995 (see Table 1). Therefore, we now consider a transformation of the above Cournot game due to coopetition which is the contribution of our paper to both coopetition and Cournot games research fields.

Consider the vector of variables $W:=\left(w_{1}, w_{2}\right)$ and extend the Cournot game. In so doing, let $\pi_{i}$ denote firm $i$ 's profit function. Furthermore, assume that the inverse demand function is linear in total production of firms, whose associated individual production level is shown by $q_{i}$. We also assume that the cost of cooperation incurred to each firm is quadratic in the cooperation level $w_{i}$. The justification of the assumption is diminishing returns in case of excessive cooperation effort (see e.g., Lida [64]). Therefore, the mathematical model of firm $i$ 's profit function is

$$
\begin{aligned}
\pi_{i}\left(q_{1}, q_{2}, w_{1}, w_{2}\right)= & \left(a-b\left(q_{1}+q_{2}\right)\right) q_{i}-C\left(w_{1}, w_{2}\right) q_{i} \\
& -\delta \frac{w_{i}^{2}}{2}, \quad a>0, \quad b, \delta>0, i=1,2,
\end{aligned}
$$

where $a, b$, and $\delta$ are fixed exogenous parameters.

In order to show the structural impacts of cooperation based on this approach, we next provide scenarios to determine the right level of cooperation. 
3.1. Setting the Cooperation Level Competitively (Nash Equilibrium). In the first scenario, we assume that firms take a competitive approach to the issue. Therefore, they do not share their basic information to set the level of production as well as the level of cooperation (see Ahmadi-Javid and Hoseinpour [65], e.g.). Moreover, we assume that $C\left(w_{1}, w_{2}\right)$ is linear in terms of total amount of cooperative effort. Therefore, the unit production cost of each firm would be

$$
C\left(w_{1}, w_{2}\right)=\alpha-\beta\left(w_{1}+w_{2}\right), \quad a>0, \beta>0,
$$

where $\alpha$ and $\beta$ are fixed exogenous parameters.

For notational simplicity, we define the following parameter:

$$
\gamma:=\left(\frac{b \delta}{\beta^{2}}\right)
$$

and call it coopetition index.

It is clear that the extent of effectiveness of cooperation in terms of cost reduction is limited and does not pass a certain limit in real world improvement projects. We formally define this intuitive idea by demanding that the coopetition index $\gamma$ is significant; that is, $\gamma>2$. Since the total market demand $a$ must be sufficiently large but not unlimited to allow for competition of the two firms, in this model, we define this notion formally by the condition $\alpha<a<\alpha_{\gamma}$, where $\alpha_{\gamma}=3 \gamma \alpha / 2$.

Proposition 1. If the total market demand is sufficiently large but not unlimited and the coopetition index is significant, there exists a unique feasible Nash equilibrium in which $q_{1}^{*}=q_{2}^{*}=$ $\delta(a-\alpha) /\left(3 b \delta-2 \beta^{2}\right), w_{1}^{*}=w_{2}^{*}=\beta(a-\alpha) /\left(3 b \delta-2 \beta^{2}\right)$, and $\pi_{1}^{*}=\pi_{2}^{*}=\left(\delta(a-\alpha)^{2}\left(2 b \delta-\beta^{2}\right)\right) / 2\left(3 b \delta-2 \beta^{2}\right)^{2}$.

Proof. In order to find production and cooperation levels in Nash equilibrium, we form the best response functions and solve the simultaneous equations. Replacing (4) in (3) and taking derivatives of both firms' profit functions in terms of both $q_{i}$ and $w_{i}$ and equating to zero, we have

$$
\begin{aligned}
& \frac{\partial \pi_{1}\left(q_{1}, q_{2}^{*}, w_{1}, w_{2}^{*}\right)}{\partial q_{1}}=0, \\
& \frac{\partial \pi_{1}\left(q_{1}, q_{2}^{*}, w_{1}, w_{2}^{*}\right)}{\partial w_{1}}=0, \\
& \frac{\partial \pi_{2}\left(q_{1}^{*}, q_{2}, w_{1}^{*}, w_{2}\right)}{\partial q_{2}}=0, \\
& \frac{\partial \pi_{2}\left(q_{1}^{*}, q_{2}, w_{1}^{*}, w_{2}\right)}{\partial w_{2}}=0 .
\end{aligned}
$$

Solving the above system of equations, the level of production and cooperation would be as follow:

$$
\begin{aligned}
& q_{1}^{*}=q_{2}^{*}=\frac{\delta(a-\alpha)}{3 b \delta-2 \beta^{2}} \geq 0, \\
& w_{1}^{*}=w_{2}^{*}=\frac{\beta(a-\alpha)}{3 b \delta-2 \beta^{2}} \geq 0 .
\end{aligned}
$$

Note that since the total market demand is sufficiently large but not unlimited and the coopetition index is significant, the above equilibrium results are feasible. Furthermore, the equilibrium results are unique because the following second order conditions hold due to the assumption that the coopetition index is significant:

$$
\begin{gathered}
\left|\begin{array}{ll}
\frac{\partial^{2} \pi_{1}\left(q_{1}, q_{2}^{*}, w_{1}, w_{2}^{*}\right)}{\partial q_{1}^{2}} & \frac{\partial \pi_{1}\left(q_{1}, q_{2}^{*}, w_{1}, w_{2}^{*}\right)}{\partial q_{1} \partial w_{1}} \\
\frac{\partial \pi_{1}\left(q_{1}, q_{2}^{*}, w_{1}, w_{2}^{*}\right)}{\partial w_{1} \partial q_{1}} & \frac{\partial^{2} \pi_{1}\left(q_{1}, q_{2}^{*}, w_{1}, w_{2}^{*}\right)}{\partial w_{1}^{2}}
\end{array}\right| \\
=\left|\begin{array}{cc}
-2 b & \beta \\
\beta & -\delta
\end{array}\right|=2 b \delta-\beta^{2}>0, \quad-2 b<0 .
\end{gathered}
$$

Since the total market demand is sufficiently large but not unlimited and the coopetition index is significant, the following conditions also hold:

$$
\begin{gathered}
a-b\left(q_{1}^{*}+q_{2}^{*}\right) \geq 0, \\
\alpha-\beta\left(w_{1}^{*}+w_{2}^{*}\right) \geq 0 .
\end{gathered}
$$

This completes the proof.

Property 1. If the total market demand is sufficiently large but not unlimited and the coopetition index is significant, there exists a unique feasible Nash equilibrium in which coopetitive Cournot duopoly is preferred over the classic Cournot duopoly unless the cooperation cost is considerably unaffordable.

Proof. In a classic Cournot duopoly model (Cournot [62]), each firm has the production level of $q=(a-\alpha) / 3 b$ and the profit function of $\pi=(a-\alpha)^{2} / 9 b$. For $\delta=8 \beta^{2} / 15 b$, both models are equal in terms of profitability; that is, $\pi_{1}^{*}=$ $\pi_{2}^{*}=\pi$. However, $\delta=8 \beta^{2} / 15 b<2 \beta^{2} / 3 b$ which contradicts the assumption that the coopetition index is significant. Both models are equal in terms of profitability only if $\delta$ is sufficiently large. More formally,

$$
\lim _{\delta \rightarrow \infty} \frac{\delta(a-\alpha)^{2}\left(2 b \delta-\beta^{2}\right)}{2\left(3 b \delta-2 \beta^{2}\right)^{2}}=\frac{(a-\alpha)^{2}}{9 b} .
$$

This completes the proof.

Figure 2 shows Property 1 graphically, where $a=1000$, $\alpha=100, b=0.01$, and $\beta=0.001$.

Property 2. If the total market demand is sufficiently large but not unlimited, the coopetition index is significant, and cooperation cost is considerably unaffordable, there exists a unique feasible Nash equilibrium in which the production level of coopetitive Cournot duopoly is equal to the classic Cournot duopoly and the cooperation level vanishes.

Proof. These properties can be proven easily by analyzing the solutions obtained for the Nash equilibria in Proposition 1. This completes the proof. 




FIGURE 2: In the scenario where the cooperation level is set competitively, for different values of $\delta$, the total market demand is sufficiently large but not unlimited (see Figure 3 ) and the coopetition index is significant (see Figure 4) where $a=1000, \alpha=100, b=0.01$, and $\beta=0.001$. Therefore, according to Property 1 , at each $\delta$ there exists a unique feasible Nash equilibrium in which coopetitive Cournot duopoly is preferred over the classic Cournot duopoly unless the cooperation cost is considerably unaffordable $(\delta \rightarrow 2)$.

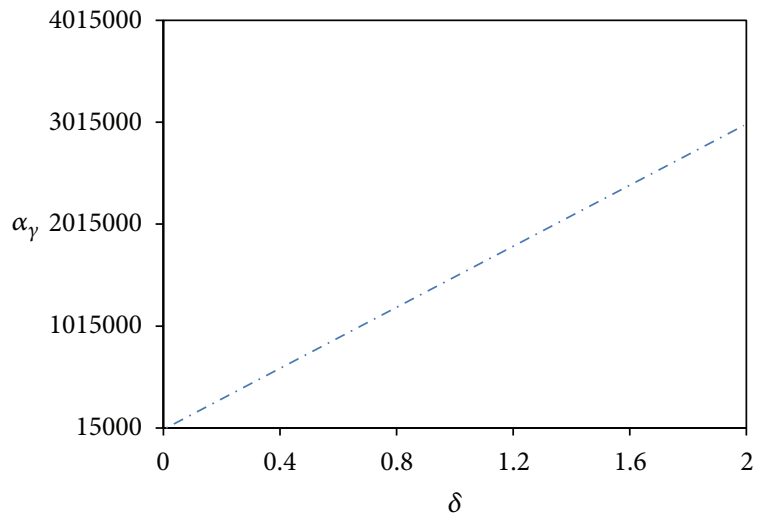

FIGURE 3: In the scenario where the cooperation level is set competitively, for different values of $\delta$, the total market demand is sufficiently large but not unlimited where $a=1000, \alpha=100$, $b=0.01$, and $\beta=0.001$.

3.2. Setting the Cooperation Level Cooperatively (Pareto Equilibrium). In the second scenario, we assume that competing firms share the information in setting both the production level and cooperation level. Therefore, the sum of profit of both parties is maximized here (see Ahmadi-Javid and Hoseinpour [65], e.g.). We also assume the symmetry of

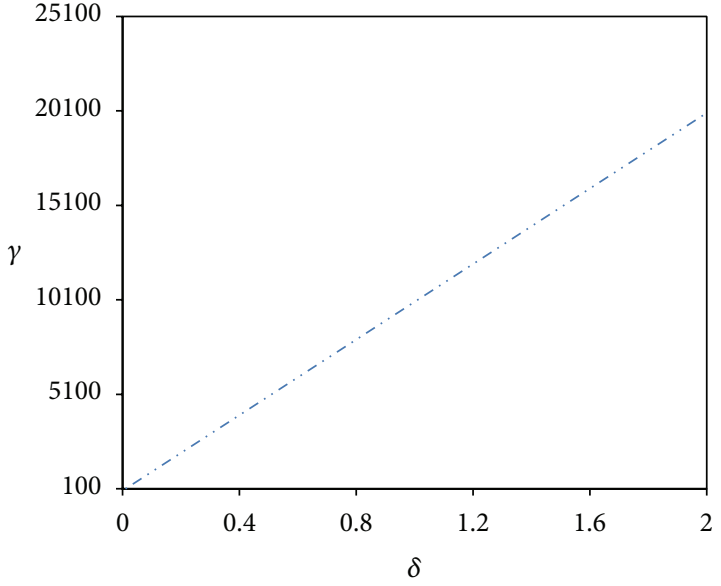

FIGURE 4: In the scenario where the cooperation level is set competitively, for different values of $\delta$, the coopetition index is significant where $a=1000, \alpha=100, b=0.01$, and $\beta=0.001$.

firms in terms of production level; that is, $q^{c}=q_{1}^{c}=q_{2}^{c}$. We have

$$
\begin{aligned}
\pi^{c}\left(q^{c}, w_{1}, w_{2}\right)= & 2\left(a-2 b q^{c}\right) q^{c}-2\left(\alpha-\beta\left(w_{1}+w_{2}\right)\right) q^{c} \\
& -\frac{\delta w_{1}^{2}}{2}-\frac{\delta w_{2}^{2}}{2} .
\end{aligned}
$$

It is clear that the extent of effectiveness of cooperation in terms of cost reduction is limited and does not pass a certain limit in the real world improvement projects. In this scenario, we formally define this intuitive idea by demanding that the coopetition index $\gamma$ is significant; that is, $\gamma>4 / 3$. Since the total market demand $a$ must be sufficiently large but not unlimited to allow for competition of the two firms, in this model, we define this notion formally by the condition $\alpha<a<\gamma \alpha$.

Proposition 2. If the total market demand is sufficiently large but not unlimited and the coopetition index is significant, there exists a unique feasible Pareto equilibrium in which $q^{c *}=\delta(a-$ $\alpha) / 4\left(b \delta-\beta^{2}\right), w_{1}^{*}=w_{2}^{*}=\beta(a-\alpha) / 2\left(b \delta-\beta^{2}\right)$, and $\pi^{c *}=$ $\delta(a-\alpha)^{2} / 4\left(b \delta-\beta^{2}\right)$.

Proof. In order to find production and cooperation levels in Pareto equilibrium, we form the best response functions and solve the simultaneous equations. Taking derivatives of profit function $\pi^{c}$ in terms of both $q^{c}$ and $w_{i}$ and equating them to zero, we have

$$
\begin{aligned}
& \frac{\partial \pi^{c}\left(q^{c}, w_{1}, w_{2}\right)}{\partial q^{c}}=0, \\
& \frac{\partial \pi^{c}\left(q^{c}, w_{1}, w_{2}\right)}{\partial w_{1}}=0, \\
& \frac{\partial \pi^{c}\left(q^{c}, w_{1}, w_{2}\right)}{\partial w_{2}}=0 .
\end{aligned}
$$


Solving the above system of equations, the level of production and cooperation would be as follow:

$$
\begin{aligned}
& q^{c *}=\frac{\delta(a-\alpha)}{4\left(b \delta-\beta^{2}\right)} \geq 0, \\
& w_{1}^{*}=w_{2}^{*}=\frac{\beta(a-\alpha)}{2\left(b \delta-\beta^{2}\right)} \geq 0 .
\end{aligned}
$$

Note that since the total market demand is sufficiently large but not unlimited and the coopetition index is significant, the above equilibrium results are feasible. Furthermore, the equilibrium results are unique because the following second order conditions hold due to the assumption that the coopetition index is significant:

$$
\mid \begin{array}{ccc}
\frac{\partial^{2} \pi^{c}\left(q^{c}, w_{1}, w_{2}\right)}{\partial q^{c 2}} & \frac{\partial^{2} \pi^{c}\left(q^{c}, w_{1}, w_{2}\right)}{\partial q^{c} \partial w_{1}} & \frac{\partial^{2} \pi^{c}\left(q^{c}, w_{1}, w_{2}\right)}{\partial q^{c} \partial w_{2}} \\
\frac{\partial^{2} \pi^{c}\left(q^{c}, w_{1}, w_{2}\right)}{\partial w_{1} \partial q^{c}} & \frac{\partial^{2} \pi^{c}\left(q^{c}, w_{1}, w_{2}\right)}{\partial w_{1}^{2}} & \frac{\partial^{2} \pi^{c}\left(q^{c}, w_{1}, w_{2}\right)}{\partial w_{1} \partial w_{2}} \\
\frac{\partial^{2} \pi^{c}\left(q^{c}, w_{1}, w_{2}\right)}{\partial w_{2} \partial q^{c}} & \frac{\partial^{2} \pi^{c}\left(q^{c}, w_{1}, w_{2}\right)}{\partial w_{2} \partial w_{1}} & \frac{\partial^{2} \pi^{c}\left(q^{c}, w_{1}, w_{2}\right)}{\partial w_{2}^{2}} \\
=-6 b \delta^{2}+b \beta^{2} \delta<0, & \\
6 b \delta-4 \beta^{2}>0, & -6 b<0 .
\end{array}
$$

Since the total market demand is sufficiently large but not unlimited and the coopetition index is significant, the following conditions also hold:

$$
\begin{gathered}
a-2 b\left(q^{c *}\right) \geq 0, \\
\alpha-\beta\left(w_{1}^{*}+w_{2}^{*}\right) \geq 0 .
\end{gathered}
$$

This completes the proof.

Property 3. If the total market demand is sufficiently large but not unlimited and the coopetition index is significant, there exists a unique feasible Pareto equilibrium in which coopetitive Cournot duopoly is always preferred over the classic Cournot duopoly.

Proof. In a classic Cournot duopoly model (Cournot [62]), each firm has the production level of $q=(a-\alpha) / 3 b$ and the profit function of $\pi=(a-\alpha)^{2} / 9 b$. For $\delta=-\left(4 \beta^{2} / 5 b\right)$, both models are equal in terms of profitability; that is, $\pi^{C}=\pi$, a value which contradicts the assumption that the coopetition index is significant. In contrast to the Property 2, the two models are not even equal as $\delta \rightarrow \infty$ :

$$
\lim _{\delta \rightarrow \infty} \frac{\delta(a-\alpha)^{2}}{4\left(b \delta-\beta^{2}\right)}=\frac{(a-\alpha)^{2}}{4 b}>\frac{2(a-\alpha)^{2}}{9 b} .
$$

This completes the proof.

Figure 5 shows Property 3 graphically, where $a=1000$, $\alpha=100, b=0.1$, and $\beta=0.01$. The above property

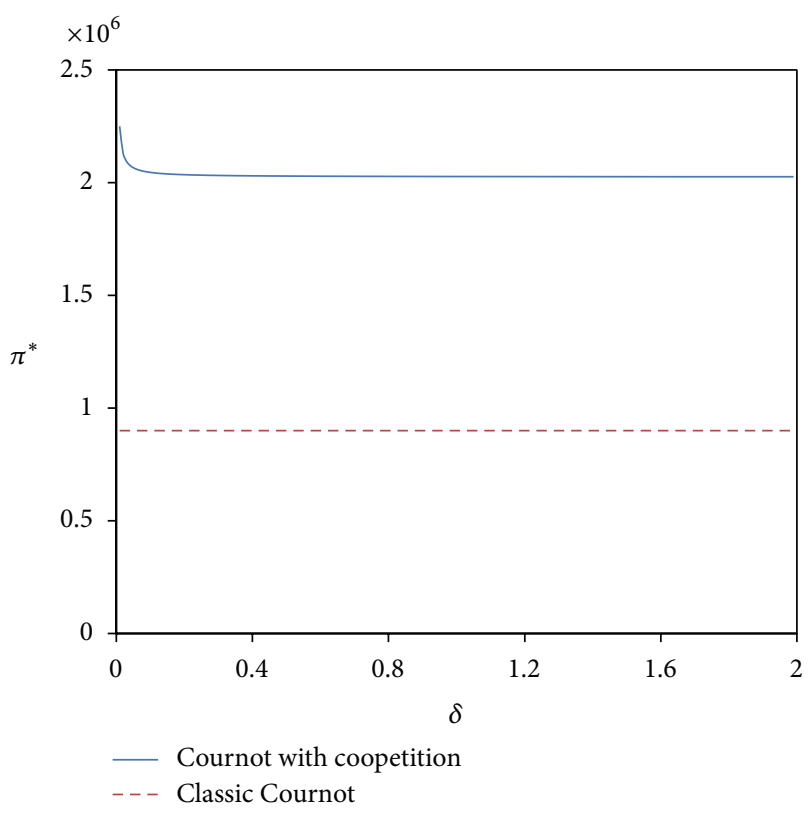

Figure 5: In the scenario where the cooperation level is set cooperatively, for different values of $\delta$, the total market demand is sufficiently large but not unlimited (see Figure 6 ) and the coopetition index is significant (see Figure 7) where $a=1000, \alpha=100, b=0.1$, and $\beta=0.01$. Therefore, according to Property 3 , at each $\delta$ there exists a unique feasible Pareto equilibrium in which coopetitive Cournot duopoly is always preferred over the classic Cournot duopoly.

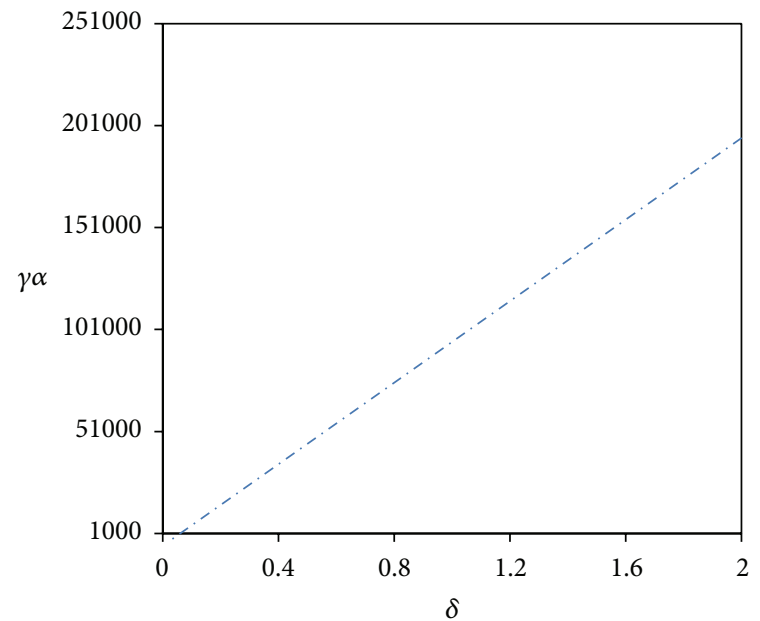

Figure 6: In the scenario where the cooperation level is set cooperatively, for different values of $\delta$, the total market demand is sufficiently large but not unlimited where $a=1000, \alpha=100, b=0.1$, and $\beta=0.01$.

has an interesting practical implication. In a setting where two firms cooperate and compete simultaneously, if levels of production and cooperation are determined cooperatively, the total profit gained is always more than a classic Cournot duopoly regardless of the cost of cooperation. This result intensifies and validates the previous empirical claims that 


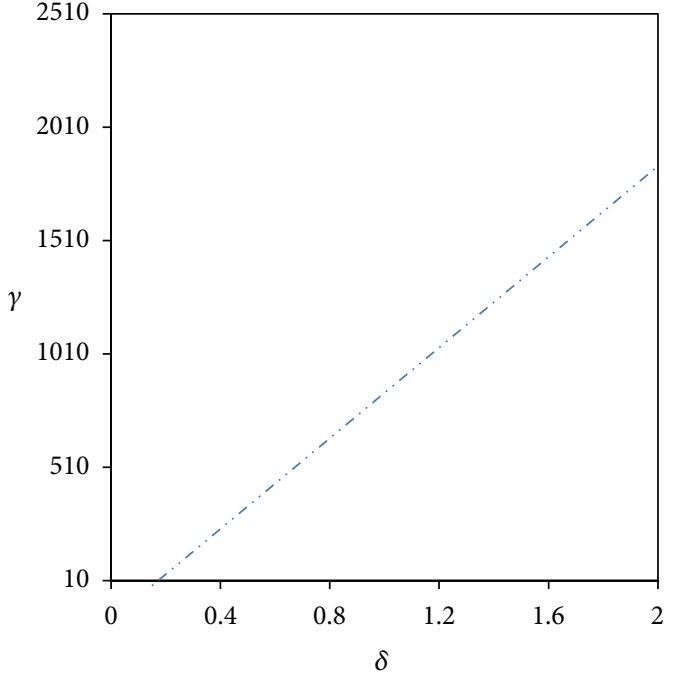

FIGURE 7: In the scenario where the cooperation level is set cooperatively, for different values of $\delta$, the coopetition index is significant where $a=1000, \alpha=100, b=0.1$, and $\beta=0.01$.

coopetition makes the total pie of profits larger (see Table 1 and references therein).

Property 4. If the total market demand is sufficiently large but not unlimited, the coopetition index is significant and cooperation cost is considerably unaffordable; there exists a unique feasible Pareto equilibrium in which the production level of coopetitive Cournot duopoly is less than the classic Cournot duopoly and the cooperation level vanishes.

Proof. These properties can be proven easily by analyzing the solutions obtained for the Pareto equilibria in Proposition 2. This completes the proof.

The lower level of production in the case of cooperation as indicated by Property 4 is justified by the virtual monopoly that forms as a result of cooperation between firms which motivates them to produce less so as to control the market price of the product.

\section{Discussion}

In the previous section, we analyzed two scenarios of coopetition between two similar suppliers where we analytically proved the superiority of coopetitive relationship over the classic pure competition. We now provide our main result in Proposition 3.

Proposition 3. If the total market demand is sufficiently large but not unlimited and the coopetition index is significant in the sense of Nash scenario, for each $\delta$, Pareto coopetitive Cournot duopoly is preferred over the Nash coopetitive Cournot duopoly.

Proof. This proposition can be proven easily by analyzing the solutions obtained for the Nash and Pareto equilibria in Propositions 1 and 2. This completes the proof.

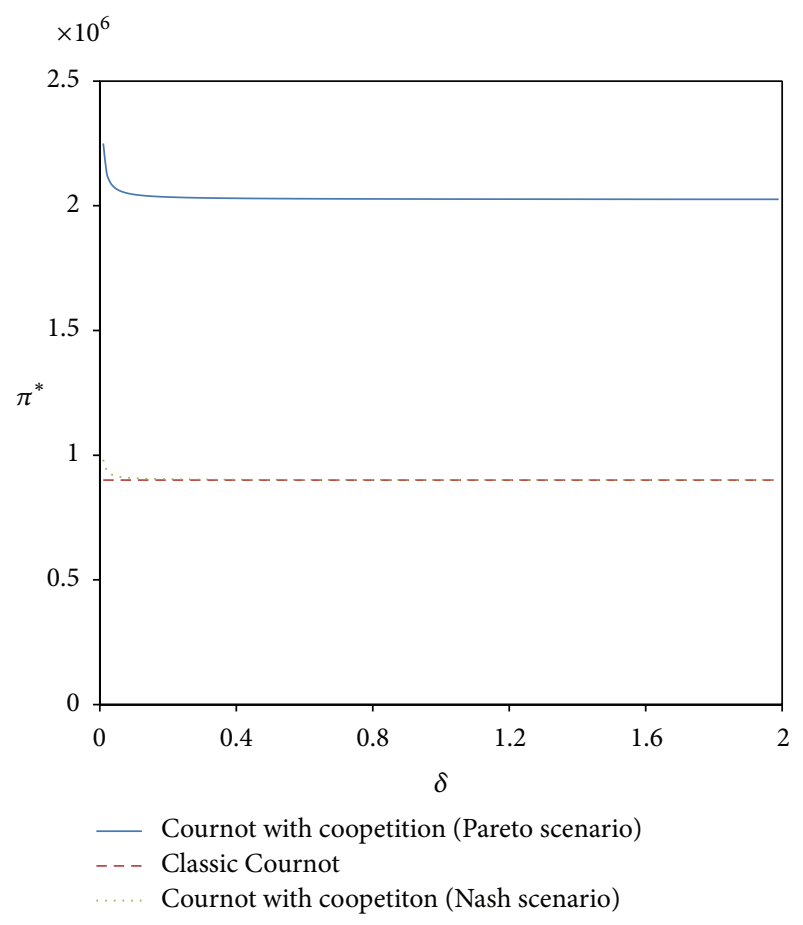

Figure 8: The total market demand is sufficiently large but not unlimited and the coopetition index is significant in the sense of Nash scenario, where $a=1000, \alpha=100, b=0.1$, and $\beta=$ 0.01 . Therefore, according to Proposition 3, for different values of $\delta$, Pareto coopetitive Cournot duopoly is preferred over the Nash coopetitive Cournot duopoly.

As it can be inferred from Figure 8, when the coopetition parameters are determined cooperatively (scenario 2), more profit is expected than the opposite case where the parameters are set competitively. This observation further validates the importance of cooperation as an interfirm strategy to gain competitive advantage which was previously shown through empirical and conceptual analyses (see e.g., Bengtsson and Kock [9]). Moreover, the increasing rate (Figure 1) of applying coopetition strategy to handle within the firm, interindustry, and intraindustry relationships (Dagnino and Padula [4]) magnifies the importance of such coopetition models to tailor coopetitive strategies because as Ritala and HurmelinnaLaukkanen [39] indicate the success of a coopetitive strategy lies upon factors determining firms' value creation and value appropriations.

\section{Conclusion and Recommendation for Future Research}

In this paper, we proposed, we consider that those parameters of the situation under study are affected as a result of coopetition, as a function of level of cooperation contributed by each firm. We conclude based on our mathematical analysis that coopetition is preferred over pure competition in terms of profitability which validates the existing empirical literature on the advantages of coopetition. As the strategy is expected to be used in more real life situations, we propose our paper 
to apply our modeling approach to analyze future situations where coopetition is under evaluation to be chosen as the firm's strategy. Therefore, we expect future research models particularly in the area of supply chain management to apply such approaches to embed the concept of coopetition within the model, the importance of which lies in determining the right level of cooperation so as to guarantee the strategy success.

\section{Conflict of Interests}

The authors declare that there is no conflict of interests regarding the publication of this paper.

\section{References}

[1] W. T. Walker, "Emerging trends in supply chain architecture," International Journal of Production Research, vol. 43, no. 16, pp. 3517-3528, 2005.

[2] S. Wadhwa, M. Mishra, F. T. S. Chan, and Y. Ducq, "Effects of information transparency and cooperation on supply chain performance: a simulation study," International Journal of Production Research, vol. 48, no. 1, pp. 145-166, 2010.

[3] A. M. Brandenburger and B. J. Nalebuff, Coopetition, Doubleday, New York, NY, USA, 1996.

[4] G. B. Dagnino and G. Padula, "Coopetition strategy: a new kind of inter-firm dynamics for value creation," in Proceedings of the European Academy of Management 2nd Annual Conference on Innovative Research in Management (EURAM '02), Stockholm, Sweden, May 2002.

[5] G. B. Dagnino and E. Rocco, Coopetition Strategy: Theory, Experiments and Cases, Routledge, London, UK, 2009.

[6] T. R. Eikebrokk and D. H. Olsen, "Co-opetition and e-business success in SMEs: an empirical investigation of European SMEs," in Proceedings of the 38th Annual Hawaii International Conference on System Sciences, p. 162, Big Island, Hawaii, USA, January 2005.

[7] H. Gurnani, M. Erkoc, and Y. Luo, "Impact of product pricing and timing of investment decisions on supply chain coopetition," European Journal of Operational Research, vol. 180, no. 1, pp. 228-248, 2007.

[8] M. Nagarajan and G. Sošić, "Game-theoretic analysis of cooperation among supply chain agents: review and extensions," European Journal of Operational Research, vol. 187, no. 3, pp. 719-745, 2008.

[9] M. Bengtsson and S. Kock, "'Coopetition' in business networks-to cooperate and compete simultaneously," Industrial Marketing Management, vol. 29, no. 5, pp. 411-426, 2000.

[10] E. G. Carayannis and J. Alexander, "Virtual, wireless mannah: a co-opetitive analysis of the broadband satellite industry," Technovation, vol. 21, no. 12, pp. 759-766, 2001.

[11] H. I. M. De Vlaam and W. M. De Jong, "Infrastructure coopetition and the creation of value: an Anglo-Dutch comparison of regulatory regimes for the provision of rail and telephony services," International Journal of Technology, Policy and Management, vol. 2, no. 2, pp. 125-143, 2002.

[12] M. Levy, C. Loebbecke, and P. Powell, "SMEs, co-opetition and knowledge sharing: the role of information systems," European Journal of Information Systems, vol. 12, no. 1, pp. 3-17, 2003.
[13] M. Soekijad and E. Andriessen, "Conditions for knowledge sharing in competitive alliances," European Management Journal, vol. 21, no. 5, pp. 578-587, 2003.

[14] D.-W. Song, "Port co-opetition in concept and practice," Maritime Policy and Management, vol. 30, no. 1, pp. 29-44, 2003.

[15] Y. Luo, "A coopetition perspective of MNC-host government relations," Journal of International Management, vol. 10, no. 4, pp. 431-451, 2004.

[16] A. L.-P. Cheng, "ICT industry development strategies and the formation of industrial innovation systems on the two sides of the Taiwan Strait," International Journal of Technology Management, vol. 32, no. 3-4, pp. 264-276, 2005.

[17] Y. Luo, "Toward coopetition within a multinational enterprise: a perspective from foreign subsidiaries," Journal of World Business, vol. 40, no. 1, pp. 71-90, 2005.

[18] D. R. Gnyawali, J. He, and R. Madhavan, "Impact of co-opetition on firm competitive behavior: an empirical examination," Journal of Management, vol. 32, no. 4, pp. 507-530, 2006.

[19] X. Luo, R. J. Slotegraaf, and X. Pan, "Cross-functional "coopetition": the simultaneous role of cooperation and competition within firms," Journal of Marketing, vol. 70, no. 2, pp. 67-80, 2006.

[20] J. Reaidy, P. Massotte, and D. Diep, "Comparison of negotiation protocols in dynamic agent-based manufacturing systems," International Journal of Production Economics, vol. 99, no. 1-2, pp. 117-130, 2006.

[21] Y. Luo, "A coopetition perspective of global competition," Journal of World Business, vol. 42, no. 2, pp. 129-144, 2007.

[22] O. Brandes, S. Brege, P.-O. Brehmer, and J. Lilliecreutz, "Chambre separée in product development: vertically mediated coopetition in the automotive supply chain," International Journal of Automotive Technology and Management, vol. 7, no. 2-3, pp. 168183, 2007.

[23] J. López-Gómez and M. Molina-Meyer, "Biodiversity through co-opetition," Discrete and Continuous Dynamical Systems B, vol. 8, no. 1, pp. 187-205, 2007.

[24] A. Barretta, "The functioning of co-opetition in the healthcare sector: an explorative analysis," Scandinavian Journal of Management, vol. 24, no. 3, pp. 209-220, 2008.

[25] W. L. Bojar and L. Drelichowski, "Analysis of tendencies in agribusiness networking coopetition in Poland and in the partner countries," Journal of Central European Agriculture, vol. 9, no. 3, pp. 445-456, 2008.

[26] K.-S. Chin, B. L. Chan, and P.-K. Lam, "Identifying and prioritizing critical success factors for coopetition strategy," Industrial Management and Data Systems, vol. 108, no. 4, pp. 437-454, 2008.

[27] P. E. Eriksson, "Achieving suitable coopetition in buyer-supplier relationships: the case of Astrazeneca," Journal of Business-toBusiness Marketing, vol. 15, no. 4, pp. 425-454, 2008.

[28] Z. Min, D. Feiqi, and W. Sai, "Coordination game model of coopetition relationship on cluster supply chains $* *$ This project was supported by the National Natural Science Foundation of China (60374023) and the Natural Science Foundation of Guangdong Province (011629)," Journal of Systems Engineering and Electronics, vol. 19, no. 3, pp. 499-506, 2008.

[29] Y. Wang and S. Krakover, "Destination marketing: competition, cooperation or coopetition?" International Journal of Contemporary Hospitality Management, vol. 20, no. 2, pp. 126-141, 2008.

[30] N. Bakshi and P. Kleindorfer, "Coopetition and investment for supply-chain resilience," Production and Operations Management, vol. 18, no. 6, pp. 583-603, 2009. 
[31] P. Baumard, "An asymmetric perspective on coopetitive strategies," International Journal of Entrepreneurship and Small Business, vol. 8, no. 1, pp. 6-22, 2009.

[32] A. Brolø, "Innovative coopetition: the strength of strong ties," International Journal of Entrepreneurship and Small Business, vol. 8, no. 1, pp. 110-134, 2009.

[33] B. Cassiman, M. C. Di Guardo, and G. Valentini, “Organising R\&D projects to profit from innovation: insights from coopetition," Long Range Planning, vol. 42, no. 2, pp. 216-233, 2009.

[34] W. Czakon, "Power asymmetries, flexibility and the propensity to coopete: An empirical investigation of SMEs' relationships with franchisors," International Journal of Entrepreneurship and Small Business, vol. 8, no. 1, pp. 44-60, 2009.

[35] D. R. Gnyawali and B.-J. Park, "Co-opetition and technological innovation in small and medium-sized enterprises: a multilevel conceptual model," Journal of Small Business Management, vol. 47, no. 3, pp. 308-330, 2009.

[36] G. Gueguen, "Coopetition and business ecosystems in the information technology sector: the example of Intelligent Mobile Terminals," International Journal of Entrepreneurship and Small Business, vol. 8, no. 1, pp. 135-153, 2009.

[37] A. Mione, "When entrepreneurship requires coopetition: the need for standards in the creation of a market," International Journal of Entrepreneurship and Small Business, vol. 8, no. 1, pp. 92-109, 2009.

[38] G. Nadin, "Coopetition as a way to reinterpret distribution relationships with emerging automotive dealer groups," International Journal of Automotive Technology and Management, vol. 9, no. 3, pp. 316-333, 2009.

[39] P. Ritala and P. Hurmelinna-Laukkanen, "What's in it for me? Creating and appropriating value in innovation-related coopetition," Technovation, vol. 29, no. 12, pp. 819-828, 2009.

[40] F. Robert, P. Marques, and F. Le Roy, "Coopetition between SMEs: an empirical study of French professional football," International Journal of Entrepreneurship and Small Business, vol. 8, no. 1, pp. 23-43, 2009.

[41] A. Tidström, "The causes of conflict when small- and medium-sized competitors cooperate," International Journal of Entrepreneurship and Small Business, vol. 8, no. 1, pp. 74-91, 2009.

[42] C. Watanabe, S. Lei, and N. Ouchi, "Fusing indigenous technology development and market learning for greater functionality development-An empirical analysis of the growth trajectory of Canon printers," Technovation, vol. 29, no. 4, pp. 265-283, 2009.

[43] Z. Wu, T. Y. Choi, and M. J. Rungtusanatham, "Supplier-supplier relationships in buyer-supplier-supplier triads: implications for supplier performance," Journal of Operations Management, vol. 28, no. 2, pp. 115-123, 2010.

[44] G. Kovács and K. Spens, "Knowledge sharing in relief supply chains," International Journal of Networking and Virtual Organisations, vol. 7, no. 2-3, pp. 222-239, 2010.

[45] M. M. Wilhelm, "Managing coopetition through horizontal supply chain relations: linking dyadic and network levels of analysis," Journal of Operations Management, vol. 29, no. 7-8, pp. 663-676, 2011.

[46] A. A. Akdoğan and A. Cingšz, "An empirical study on determining the attitudes of Small and Medium Sized Businesses (SMEs) related to coopetition," in Proceedings of the 8th International Strategic Management Conference on Procedia Social and Behavioral Sciences, vol. 58, pp. 252-258, October 2012.
[47] J. Dahl, "Conceptualizing coopetition as a process: an outline of change in cooperative and competitive interactions," Industrial Marketing Management, 2013.

[48] A. Tidström, "Managing tensions in coopetition," Industrial Marketing Management, 2013.

[49] F. Achcaoucaou, P. Miravitlles, and F. León-Darder, "Knowledge sharing and subsidiary R\&D mandate development: a matter of dual embeddedness," International Business Review, vol. 23, no. 1, pp. 76-90, 2014.

[50] K. Karhu, T. Tang, and M. Hämäläinen, "Analyzing competitive and collaborative differences among mobile ecosystems using abstracted strategy networks," Telematics and Informatics, vol. 31, no. 2, pp. 319-333, 2014.

[51] J. Lipnack and J. Stamps, The TeamNet Factor: Bringing the Power of Boundary Crossing into the Heart of Your Business, John Wiley and Sons, Hoboken, NJ, USA, 1993.

[52] A. M. Brandenburger and H. W. Stuart Jr., "Value-based business strategy," Journal of Economics and Management Strategy, vol. 5, no. 1, pp. 5-24, 1996.

[53] L. D. Browning, J. M. Beyer, and J. C. Shetler, "Building cooperation in a competitive Industry: SEMATECH and the semiconductor industry," The Academy of Management Journal, vol. 38, no. 1, pp. 113-151, 1995.

[54] A. A. Lado, N. G. Boyd, and S. C. Hanlon, "Competition, cooperation, and the search for economic rents: a syncretic model," Academy of Management Review, vol. 22, no. 1, pp. 110141, 1997.

[55] D. R. Gnyawali and R. Madhavan, "Cooperative networks and competitive dynamics: a structural embeddedness perspective," Academy of Management Review, vol. 26, no. 3, pp. 431-445, 2001.

[56] Z. Wang, A. Szolnoki, and M. Perc, "Optimal interdependence between networks for the evolution of cooperation," Scientific Reports, vol. 3, article 2470, 2013.

[57] Z. Wang, A. Szolnoki, and M. Perc, "Percolation threshold determines the optimal population density for public cooperation," Physical Review E, vol. 85, no. 3, Article ID 037101, 2012.

[58] Z. Wang, C. Xia, S. Meloni, C. Zhou, and Y. Morenob, "Impact of social punishment on cooperative behavior in complex networks," Scientific Reports, vol. 3, article 3055, 2013.

[59] M. Perc and Z. Wang, "Heterogeneous aspirations promote cooperation in the prisoner's dilemma game," PLOS ONE, vol. 5, no. 12, Article ID e15117, 2010.

[60] H.-F. Zhang, R.-R. Liu, Z. Wang, H.-X. Yang, and B.-H. Wang, "Aspiration-induced reconnection in spatial publicgoods game," Europhysics Letters, vol. 94, no. 1, Article ID 18006, 2011.

[61] Y. Shoham and K. Leyton-Brown, Multiagent Systems: Algorithmic, Game Theoretic and Logical Foundations, Cambridge University Press, 2009.

[62] A. A. Cournot, Research into the Mathematical Principles of the Theory of Wealth, Mcmillan, New York, NY, USA, 1987.

[63] L. Han and A. L. Liu, "On Nash-Cournot games with price caps," Operations Research Letters, vol. 41, no. 1, pp. 92-97, 2013.

[64] T. Lida, "Coordination of cooperative cost-reduction efforts in a supply chain partnership," European Journal of Operational Research, vol. 222, no. 2, pp. 180-190, 2012.

[65] A. Ahmadi-Javid and P. Hoseinpour, "On a cooperative advertising model for a supply chain with one manufacturer and one retailer," European Journal of Operational Research, vol. 219, no. 2, pp. 458-466, 2012. 


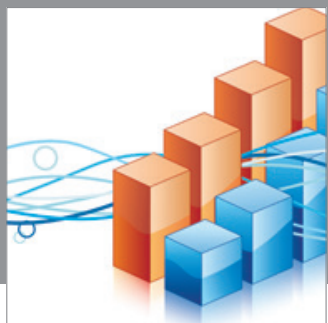

Advances in

Operations Research

mansans

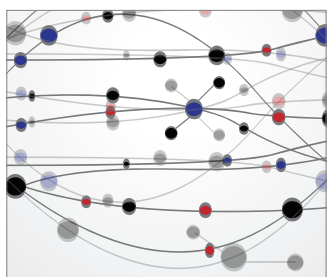

The Scientific World Journal
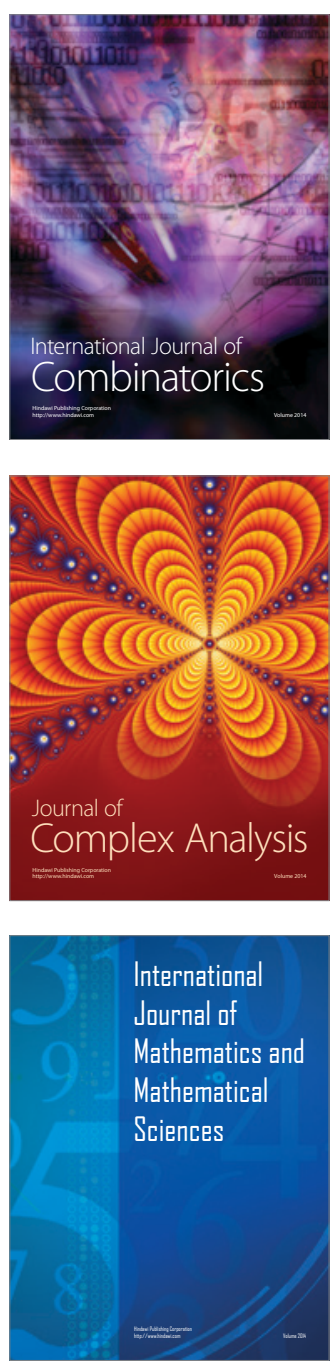
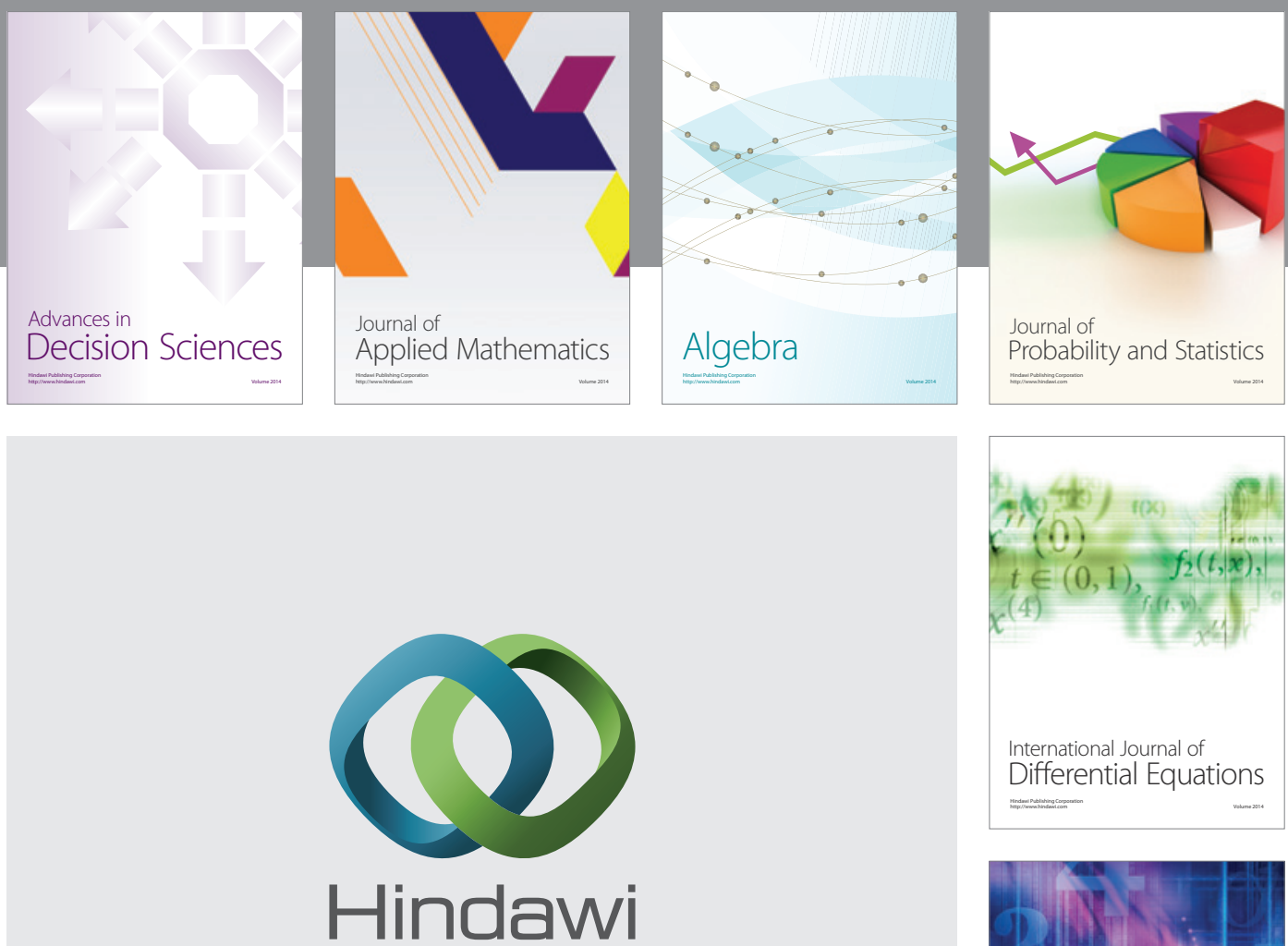

Submit your manuscripts at http://www.hindawi.com
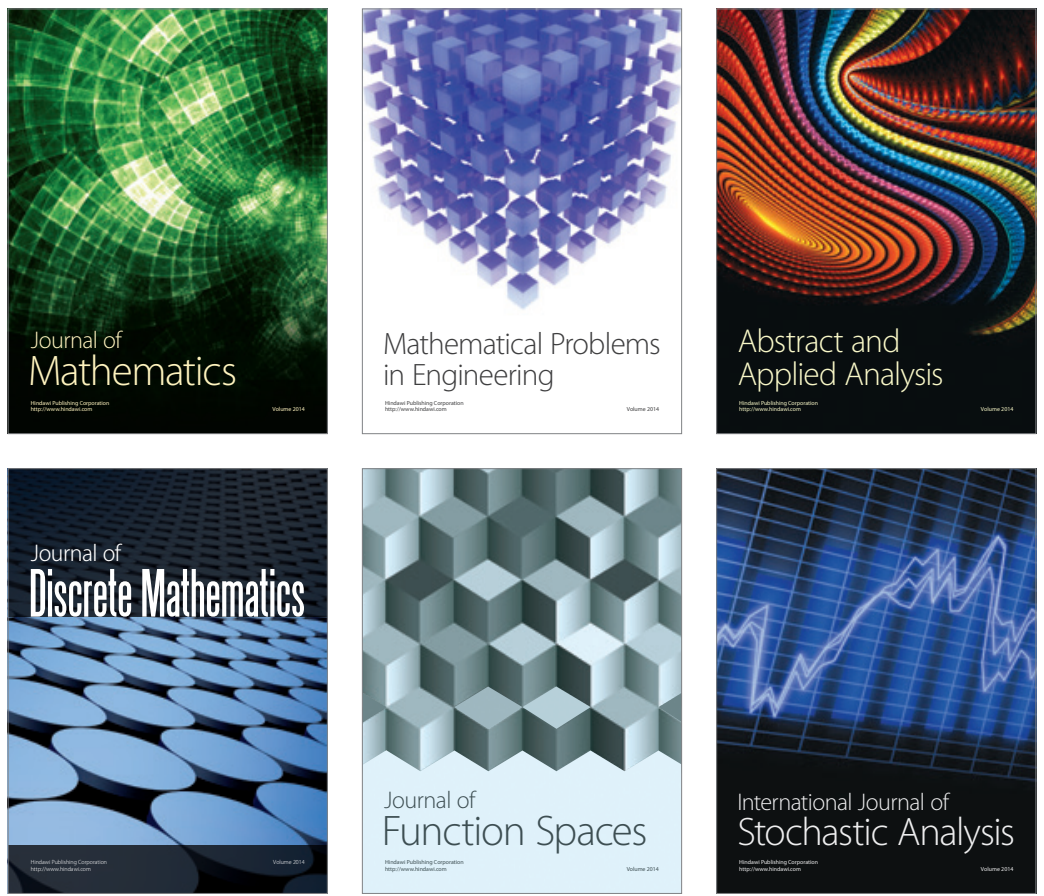

Journal of

Function Spaces

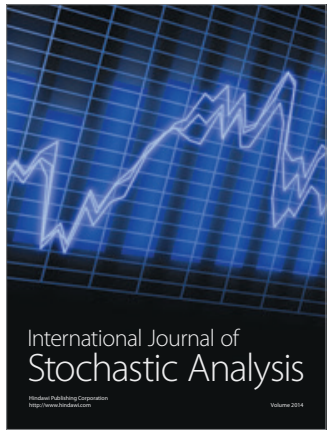

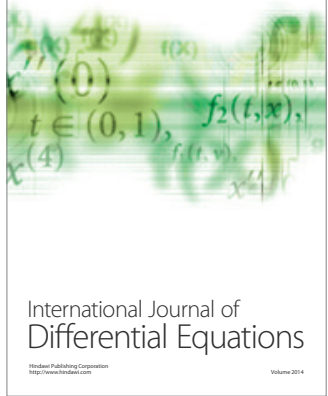
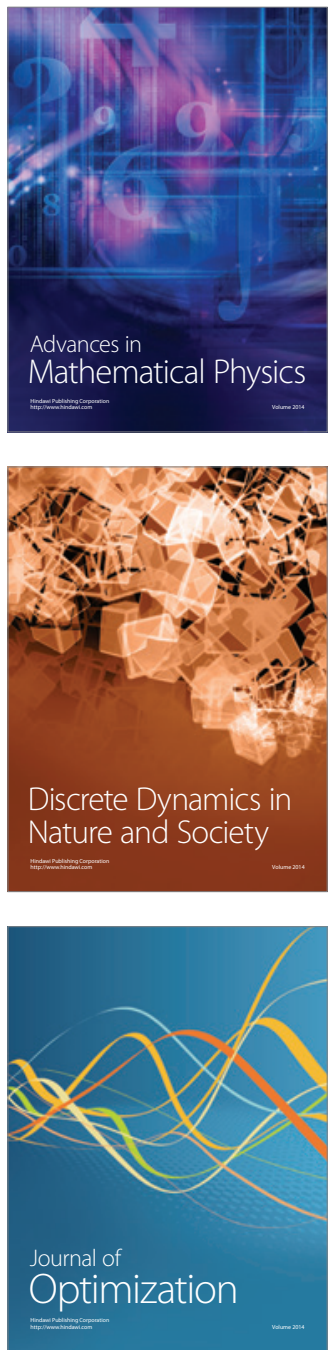